\title{
Surface Characteristics of Titanium Oxide Films Prepared by Micro-Arc Oxidation: Comparison of Direct Current Electrolysis and Pulse Electrolysis
}

\author{
M. Iwasaki ${ }^{1,2, *}$, K. Shimada ${ }^{1}$, K. Kudo ${ }^{1}$, Y. Tamagawa ${ }^{1}$ and H. Horikawa ${ }^{2}$ \\ ${ }^{1}$ Interdisciplinary Graduate School of Science and Engineering, Kinki University, Higashi-Osaka 577-8502, Japan \\ ${ }^{2}$ Liaison Center, Kinki University, Higashi-Osaka 577-8502, Japan
}

\begin{abstract}
Oxide layers formed by micro-arc oxidation (MAO) using direct current electrolysis and pulse electrolysis were characterized by scanning electron microscopy, X-ray diffraction, energy-dispersive X-ray spectroscopy and adhesive strength measurements. Ti oxide films fabricated by pulse electrolysis were found to have a significantly higher adhesive strength than those fabricated by direct current electrolysis. This can be explained by the different interface adhesive strengths between the two Ti oxide layers and the Ti substrate, as revealed by cross-sectional SEM micrographs. In addition, the dependences of the voltage and the current on the electrolysis time were investigated. [doi:10.2320/matertrans.M2010227]
\end{abstract}

(Received February 18, 2011; Accepted April 11, 2011; Published May 25, 2011)

Keywords: micro-arc oxidation, direct current electrolysis, pulse electrolysis, adhesive strength, calcium titanate

\section{Introduction}

Pure titanium and its alloys are often used as dental and orthopedic implant materials because of their good mechanical properties and high corrosion resistances. ${ }^{1-3)}$ However, they are not able to induce bone formation due to the bioinertness of the native oxide film. ${ }^{4,5)}$ Surface modifications for enhancing their biocompatibilities have been extensively investigated using physical, chemical, and electrochemical techniques. ${ }^{6-9)}$ Of these techniques, micro-arc oxidation (MAO) has recently attracted considerable interest because newly formed titanium oxide films produced by MAO are highly porous and adhere firmly to titanium. ${ }^{10-13)}$ By controlling the composition and concentration of the electrolyte, Ca- and P-containing ceramics such as hydroxyapatite have been incorporated into the surface layer by us ${ }^{14)}$ and others. ${ }^{15-17)}$

There are two kinds of MAO techniques: those that employ direct current electrolysis ${ }^{18,19)}$ and those that use pulse electrolysis. ${ }^{20,21)}$ However, to the best of our knowledge, no studies have compared the surface characteristics (e.g., surface structure, morphology, and composition) of films produced by these two electrochemical methods.

In this study, we investigated the surface characteristics of titanium oxide films fabricated by direct current electrolysis and pulse electrolysis and compared their surfaces properties, cross sections, and adhesive strengths. In addition, the dependences of the voltage and the current on the electrolysis time of the two electrolyses were studied.

\section{Materials and Methods}

\subsection{Materials}

Pure titanium plates (Showa Co., Japan) were used for both the anode and the cathode during MAO. Natural hydroxyapatite (HAp; Eccera Co.) was used without modification.

*Corresponding author, E-mail: m-iwa@apch.kindai.ac.jp
2.2 Micro-arc oxidation

2.2.1 Fabrication of anodized and HAp-fixed anodized titanium plates

A Ti plate $(30 \mathrm{~mm} \times 25 \mathrm{~mm} \times 1.0 \mathrm{~mm})$ was immersed in an electrolyte composed of $0.5 \mathrm{M}$ or $1.0 \mathrm{M} \mathrm{NaOH}-0.05 \mathrm{M}$ $\mathrm{Na}_{3} \mathrm{PO}_{4}-0.05 \mathrm{M} \mathrm{H}_{2} \mathrm{O}_{2}(0.5 \mathrm{M}$ or $1.0 \mathrm{M}$ bath $)$ at a distance of $5.0 \mathrm{~cm}$ from both electrodes. It was anodized at a constant current density of $0.2-2 \mathrm{kA} / \mathrm{m}^{2}$ in a potential of 150 or $200 \mathrm{~V}$ for 1.5-20 min by direct current electrolysis. This procedure produced an anodized titanium (AO-Ti) plate, which was washed with distilled water and dried in air. A HAp-fixed anodized titanium (HAp-AO-Ti) plate was also fabricated by adding $1-10 \mathrm{~g} / \mathrm{L}$ of HAp to the above electrolyte and performing MAO in the same manner as described above.

\subsubsection{Fabrication of pulse anodized and HAp-fixed pulse} anodized titanium plates

Using the same electrodes and electrolyte as those described in 2.2.1, MAO was performed at a constant current density of $2 \mathrm{kA} / \mathrm{m}^{2}$ in a potential of $200 \mathrm{~V}$ for $1.5-20 \mathrm{~min}$ by pulse electrolysis. This procedure produced a pulse anodized titanium (pulse-AO-Ti) plate, which was washed with distilled water and dried in air. Square waves with frequencies of $10-150 \mathrm{~Hz}$ were used for pulse electrolysis. A HAp-fixed pulse anodized titanium (HAp-pulse-AO-Ti) plate was also fabricated by adding $1-10 \mathrm{~g} / \mathrm{L}$ of HAp to the above electrolyte and applying the same pulse electrolysis method.

\subsection{Characterization of the anodized materials}

The microstructure and composition of the oxidized layer were analyzed by scanning electron microscopy (SEM; S4800 Hitachi, Japan) and energy-dispersive X-ray spectroscopy (EDX; EX-420, Horiba, Japan). The cross sectional morphologies were observed with SEM of the samples cut by use of a cross section polisher (IB-09010CP, JEOL, Japan), where the laser light was irradiated for $3 \mathrm{hr}$ at $6.00 \mathrm{kV}$ under Argon gas flow of $1.0-1.2 \mathrm{ml} / \mathrm{s}$. Phase analysis was performed by X-ray diffraction (XRD) (Rinto2500, Rigaku, Japan). The thickness of the oxidized layer was measured by 


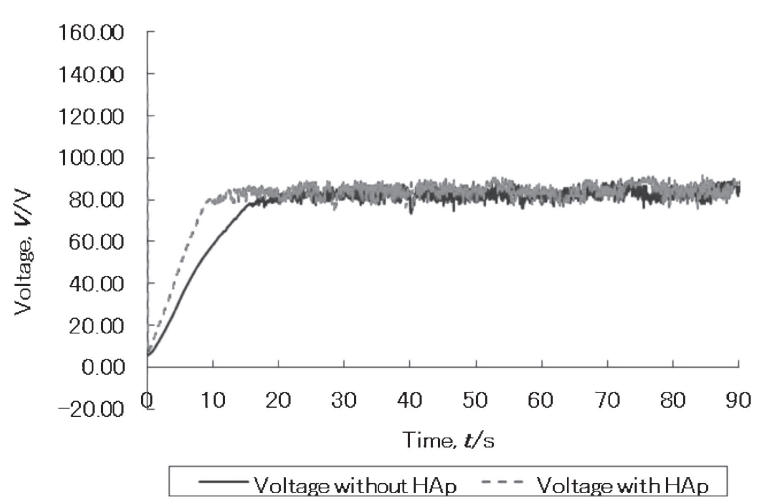

Fig. 1 Voltage vs. time in the direct current electrolysis.

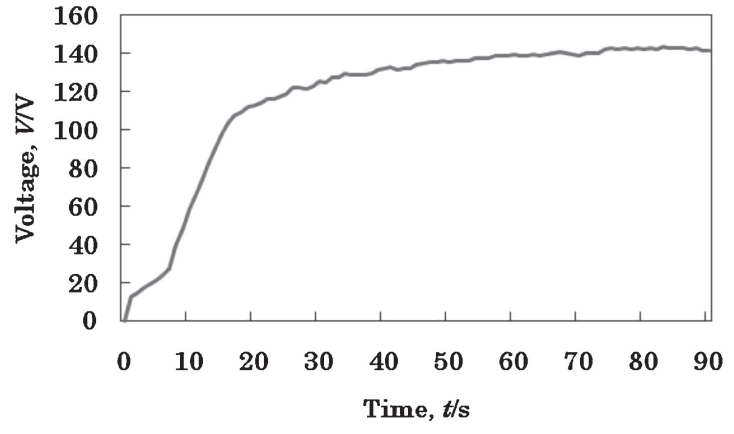

Fig. 2 Voltage vs. time in the pulse electrolysis.
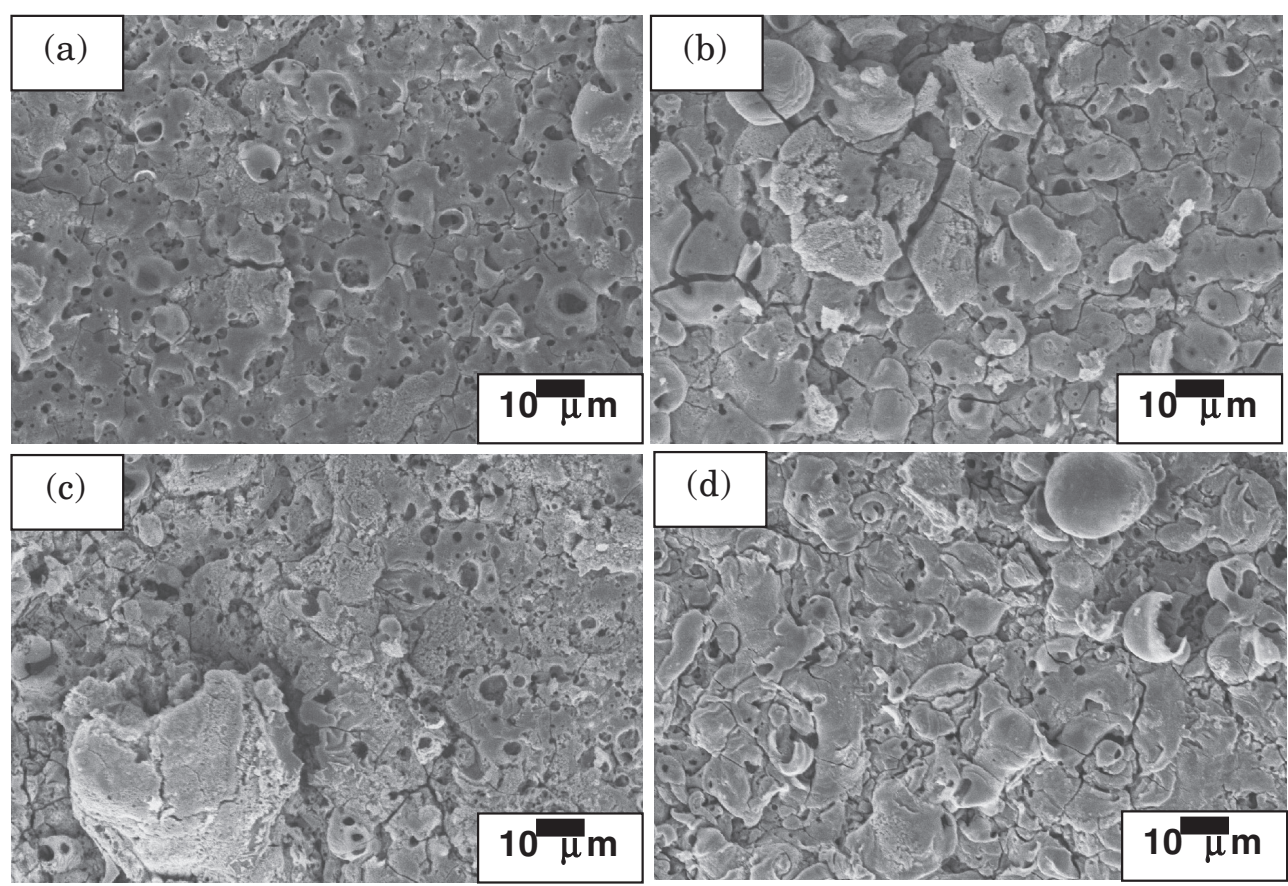

Fig. 3 Surface SEM micrographs of AO-Ti anodized by $5 \mathrm{kA} / \mathrm{m}^{2}$ of current density in $0.5 \mathrm{M} \mathrm{NaOH} \mathrm{bath}$. (a) $5 \mathrm{~min}, 0.5 \mathrm{kA} / \mathrm{m}^{2}, 0.5 \mathrm{M}$ $\mathrm{NaOH}$ bath (b) $10 \mathrm{~min}, 0.5 \mathrm{kA} / \mathrm{m}^{2}, 0.5 \mathrm{M} \mathrm{NaOH}$ bath (c) $20 \mathrm{~min}, 5 \mathrm{kA} / \mathrm{m}^{2}, 0.5 \mathrm{M} \mathrm{NaOH}$ bath (d) $5 \mathrm{~min}, 0.5 \mathrm{kA} / \mathrm{m}^{2}, 1.0 \mathrm{M} \mathrm{NaOH}$ bath.

a coating thickness meter (Isoscope MP3, Hanami, Japan; EDY-1000, Sanko, Japan).

The adhesive strength was measured by bonding samples to the adhesion strength measurement system (BA-450D, Marubishi, Japan) using cyanoacrylate adhesive (\#31701, Toagosei, Japan).

The voltage and current variation with electrolysis time was measured using an oscilloscope (8835-01, Hioki, Japan).

\section{Results and Discussion}

\subsection{Voltage $v s$. electrolysis time for anodic oxidation}

Figure 1 shows the voltage-time characteristics for direct current electrolysis at a current density of $2 \mathrm{kA} / \mathrm{m}^{2}$ for $90 \mathrm{~s}$ in the electrolyte containing $0.5 \mathrm{M} \mathrm{NaOH}$. The voltage increases sharply for about $17 \mathrm{~s}$ from the commencement of MAO with no added HAp and the titanium substrate surface is oxidized to produce a $\mathrm{TiO}_{2}$ layer without sparking. The
$\mathrm{TiO}_{2}$ layer becomes denser and thicker with increasing voltage. At a voltage of $80 \mathrm{~V}$, spark discharge starts to occur due to dielectric breakdown and the voltage remains almost constant with time, although it fluctuates slightly. ${ }^{16,18)}$ When HAp is added to the electrolyte, the spark discharge voltage is attained after about $10 \mathrm{~s}$, suggesting that either dielectric breakdown occurs due to the increase in the conductivity caused by adding HAp or a film with sufficient thickness for spark discharge is formed faster.

Figure 2 shows the voltage vs. time characteristics for pulse electrolysis without HAp with a current density of $2 \mathrm{kA} / \mathrm{m}^{2}$ and a frequency of $100 \mathrm{~Hz}$; the voltages were taken at maximum points of square waves. Similar to the direct current electrolysis, the voltage rises up sharply to $110 \mathrm{~V}$ during $18 \mathrm{~s}$, and then spark discharge initiates and the voltage increases very slowly with small fluctuation. The resulting voltage was also confirmed to be independent of the current density $\left(1.4-2 \mathrm{kA} / \mathrm{m}^{2}\right)$ and the frequency $(100-150 \mathrm{~Hz})$. 

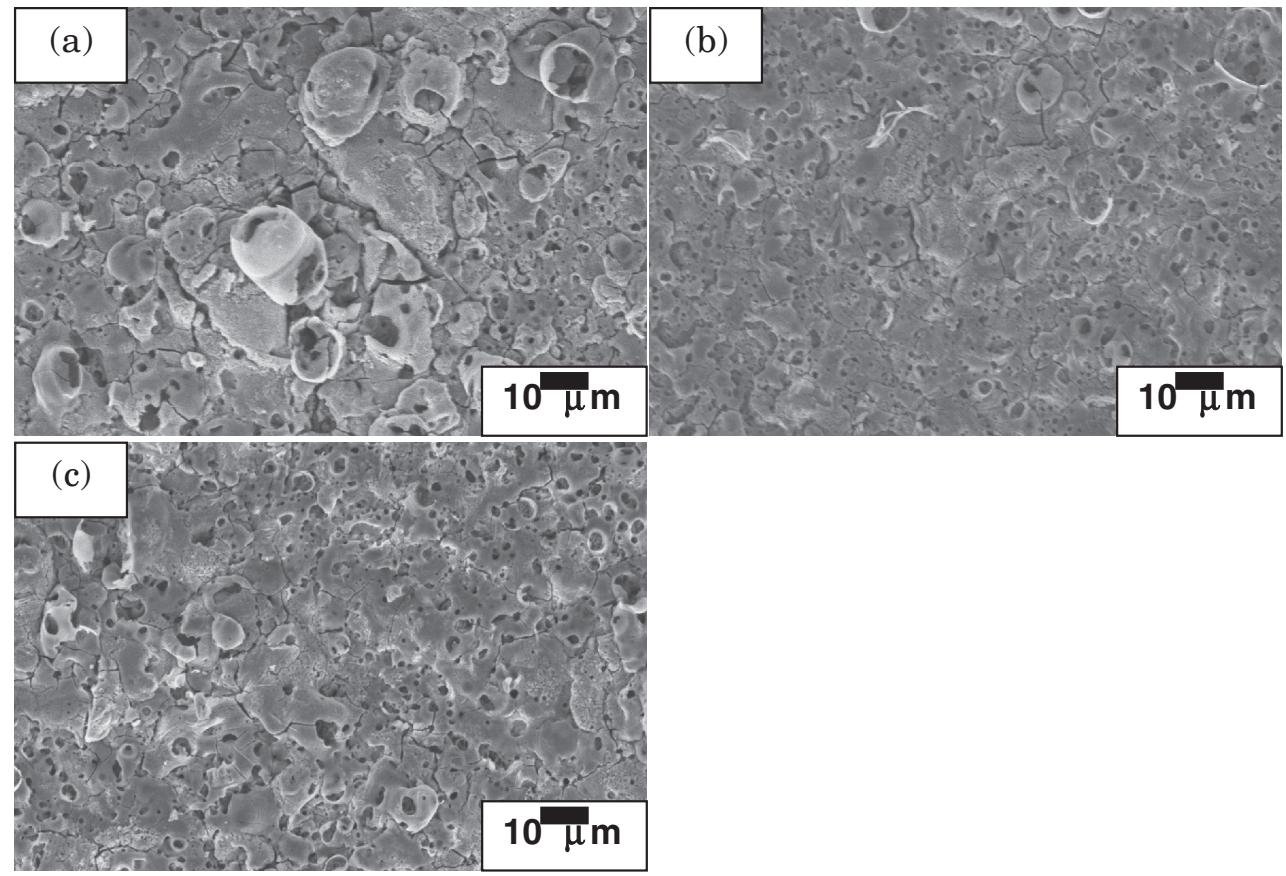

Fig. 4 Surface SEM micrographs of AO-Ti anodized for $3 \mathrm{~min}$. (a) $0.8 \mathrm{kA} / \mathrm{m}^{2}$ (b) $1.1 \mathrm{kA} / \mathrm{m}^{2}$ (c) $1.4 \mathrm{kA} / \mathrm{m}^{2}$.
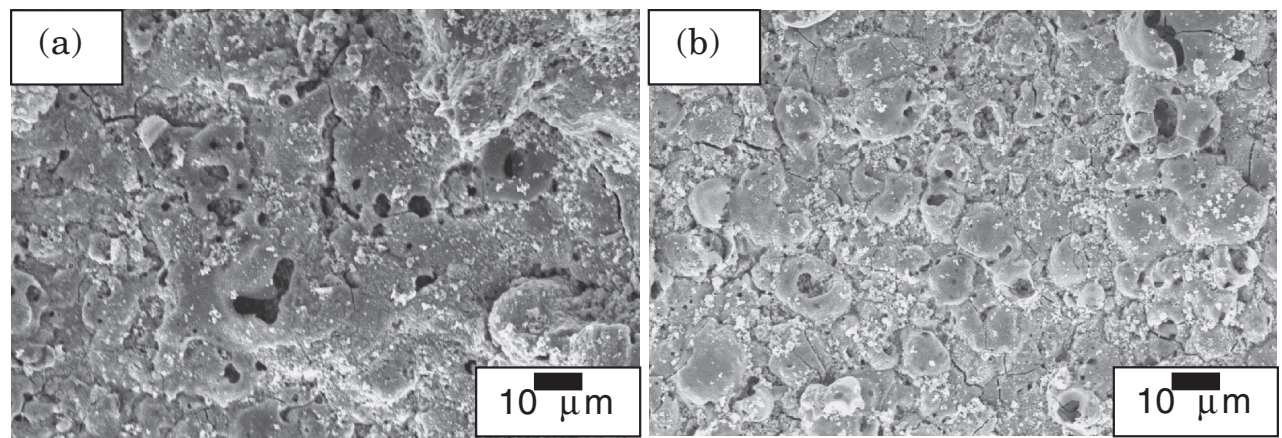

Fig. 5 Surface SEM micrographs of HAp-AO-Ti prepared with (a) $0.5 \mathrm{M} \mathrm{NaOH}$ or (b) $1.0 \mathrm{M} \mathrm{NaOH}$ bath.

\subsection{Surface SEM micrographs}

MAO was initially performed at a constant current density of $0.5 \mathrm{kA} / \mathrm{m}^{2}$ in the electrolyte consisting of $0.5 \mathrm{M}$ $\mathrm{NaOH}-0.05 \mathrm{M} \mathrm{Na}_{3} \mathrm{PO}_{4}-0.05 \mathrm{M} \mathrm{H}_{2} \mathrm{O}_{2}$ using direct current electrolysis. Figure 3 shows SEM micrographs of AO-Ti surfaces obtained after performing MAO for 5,10 , and $15 \mathrm{~min}$. The SEM micrographs reveal many pores with diameters of $1-10 \mu \mathrm{m}$ and very rough surfaces. The roughness increases with increasing MAO time. Next, MAO was performed at current densities of $0.8,1.1$, and $1.4 \mathrm{kA} / \mathrm{m}^{2}$ for 3 min (Fig. 4). The smoothness increased with increasing current density, indicating that increasing increase of travel distance of the spark discharge by increasing the current density produces more uniform and flatter oxide layers. When $1.0 \mathrm{M} \mathrm{NaOH}$ was used as the electrolyte rather than $0.5 \mathrm{M} \mathrm{NaOH}$, the surface roughness increased; this is probably due to more vigorous spark discharge by the increase in the conductivity of the electrolyte, as shown in Fig. 3(d). ${ }^{18)}$ Figure 5 shows surface SEM micrographs of a HAp-AO-Ti plate fabricated by adding HAp particles
$(10 \mathrm{~g} / \mathrm{L})$ to the above electrolyte. Many HAp particles were deposited on the surface, reducing the smoothness and uniformity of the surface. The oxidized layer of the HAp$\mathrm{AO}-\mathrm{Ti}$ plate was $12.0 \mu \mathrm{m}$ thick, whereas the AO-Ti layer was $8.2 \mu \mathrm{m}$ thick. This increase in thickness is probably because HAp particles were incorporated on and in the oxidized layer.

Figure 6 shows surface SEM micrographs of pulse-AO-Ti plates fabricated by pulse electrolysis in the electrolyte consisting of $0.5 \mathrm{M} \mathrm{NaOH}-0.05 \mathrm{M} \mathrm{Na}_{3} \mathrm{PO}_{4}-0.05 \mathrm{M} \mathrm{H}_{2} \mathrm{O}_{2}$; the current density, pulse frequency, and the electrolysis time were set to $1.4-2 \mathrm{kA} / \mathrm{m}^{2}, 100 \mathrm{~Hz}$, and $10 \mathrm{~min}$, respectively. In pulse electrolysis, dielectric breakdown occurred uniformly over the whole surface and small spark discharge was generated. These things can explain that compared to the direct current electrolysis, the surface was very smooth, on which many small pores with the diameter of $0.2-1.0 \mu \mathrm{m}$ were observed. The oxide layer thickness and the pore diameter both increased with increasing current density. Next, the frequency was increased from 10 to $150 \mathrm{~Hz}$ at a 

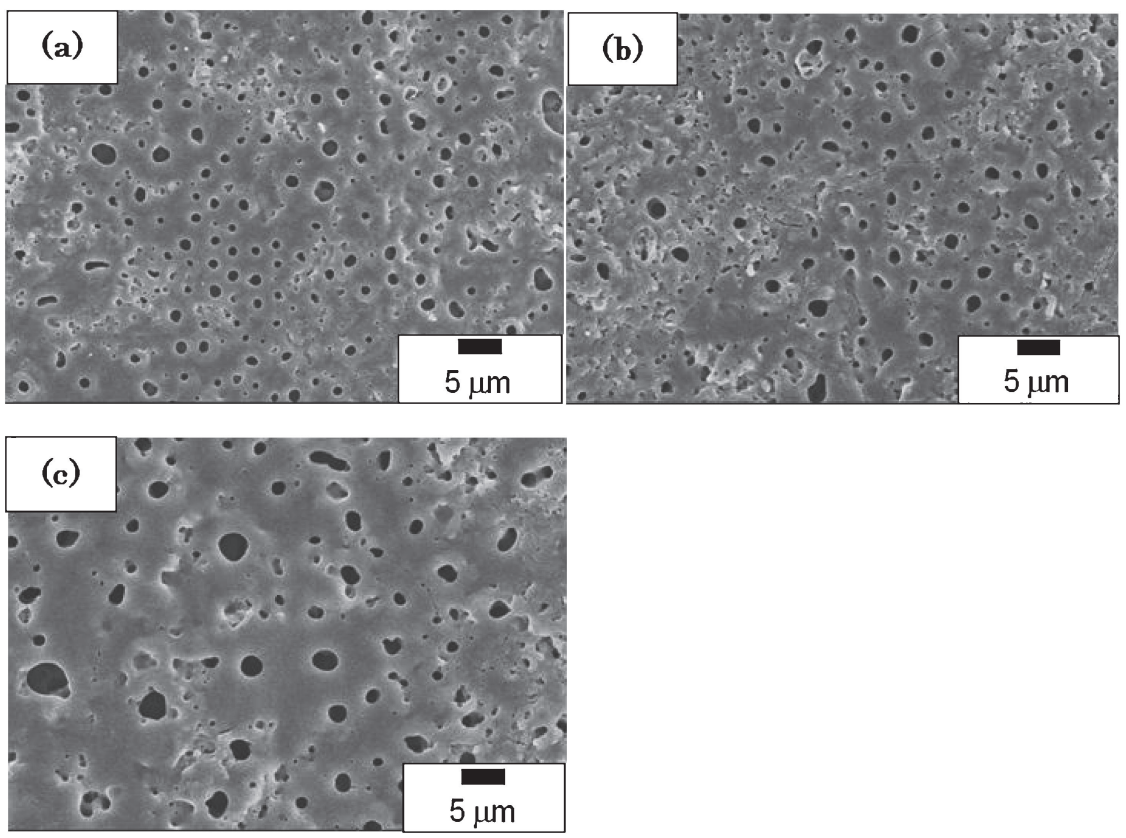

Fig. 6 Surface SEM micrographs of Pulse-AO-Ti. (a) $0 \pm 14 \mathrm{kA} / \mathrm{m}^{2}$ (b) $0 \pm 17 \mathrm{kA} / \mathrm{m}^{2}$ (c) $0 \pm 20 \mathrm{kA} / \mathrm{m}^{2}$.
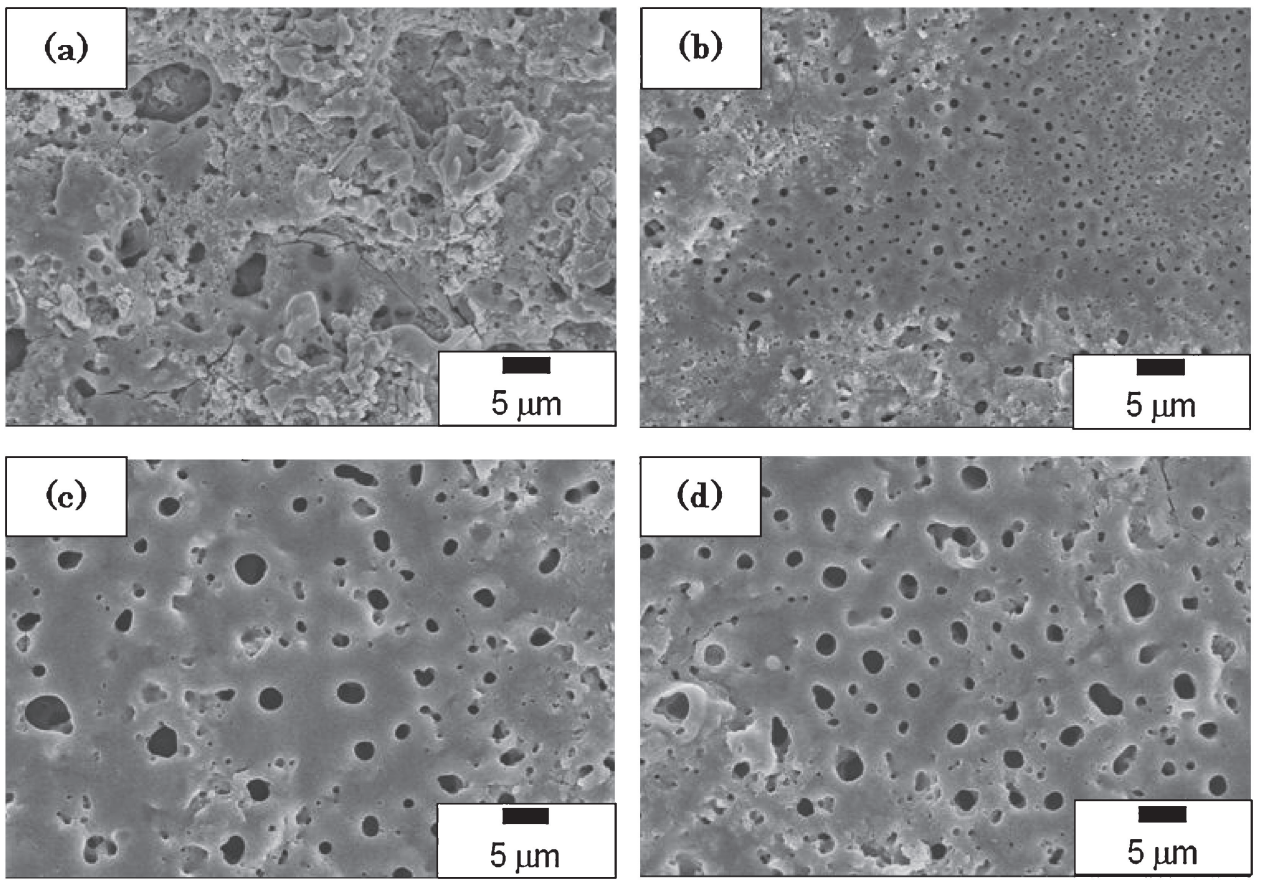

Fig. 7 Surface SEM micrographs of Pulse-AO-Ti. (a) $10 \mathrm{~Hz}$ (b) $50 \mathrm{~Hz}$ (c) $100 \mathrm{~Hz}$ (d) $150 \mathrm{~Hz}$.

constant current density of $2 \mathrm{kA} / \mathrm{m}^{2}$ for an electrolysis time of $10 \mathrm{~min}$ (see Fig. 7). The surface anodized at $10 \mathrm{~Hz}$ had a similar roughness to the AO-Ti plate, indicating that pulse electrolysis at low frequencies has a similar effect as direct current electrolysis. An oxide layer containing many small pores was formed at high frequencies. Spark discharge did not occur above $150 \mathrm{~Hz}$, probably because the pulse energy is too low to generate dielectric breakdown.

Figure 8 shows SEM micrographs of a HAp-pulse-AO-Ti plate obtained by the addition of HAp $1.0-14.0 \mathrm{~g} / \mathrm{L}$; the current density, pulse frequency, and electrolysis time were set to $2 \mathrm{kA} / \mathrm{m}^{2}, 100 \mathrm{~Hz}$, and $10 \mathrm{~min}$, respectively. The amount of HAp deposited on the surface increased with increasing amount of added HAp.

\subsection{EDX measurements}

Figure 9 shows an EDX spectrum of the Hap-AO-Ti plate made by direct current electrolysis at a current density of $0.5 \mathrm{kA} / \mathrm{m}^{2}$ for $5 \mathrm{~min}$ in the $0.5 \mathrm{M} \mathrm{NaOH}$ bath that contains $10 \mathrm{~g} / \mathrm{L} \mathrm{HAp}$. It reveals that the surface has high levels of $\mathrm{Ca}$ and $\mathrm{P}$, indicating that HAp particles were included in the oxidized film. In addition, the Ca brightnes increased with 

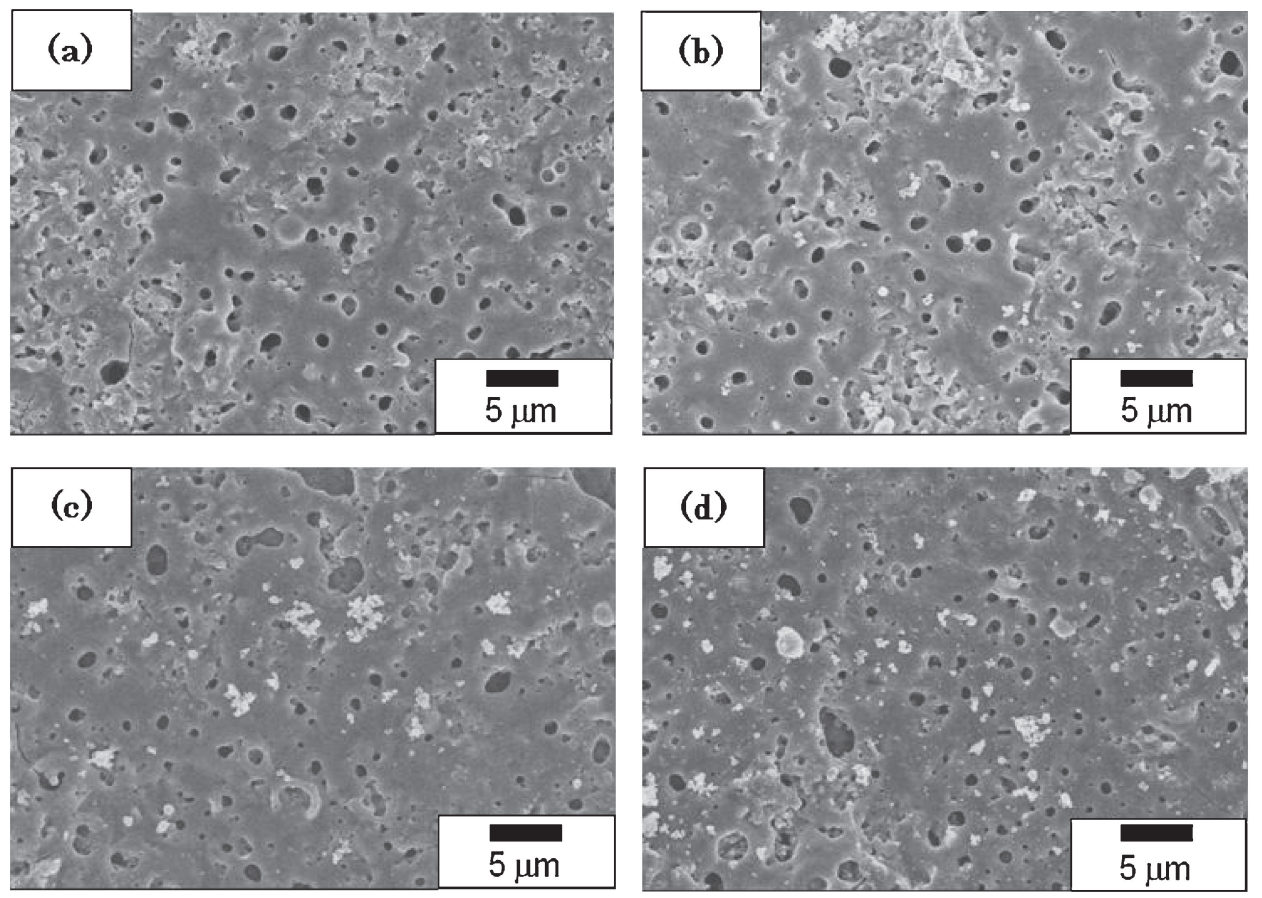

Fig. 8 Surface SEM micrographs of HAp-Pulse-AO-Ti. (a) HAp 1 g/L (b) HAp 4 g/L (c) HAp 10 g/L (d) HAp 14 g/L.
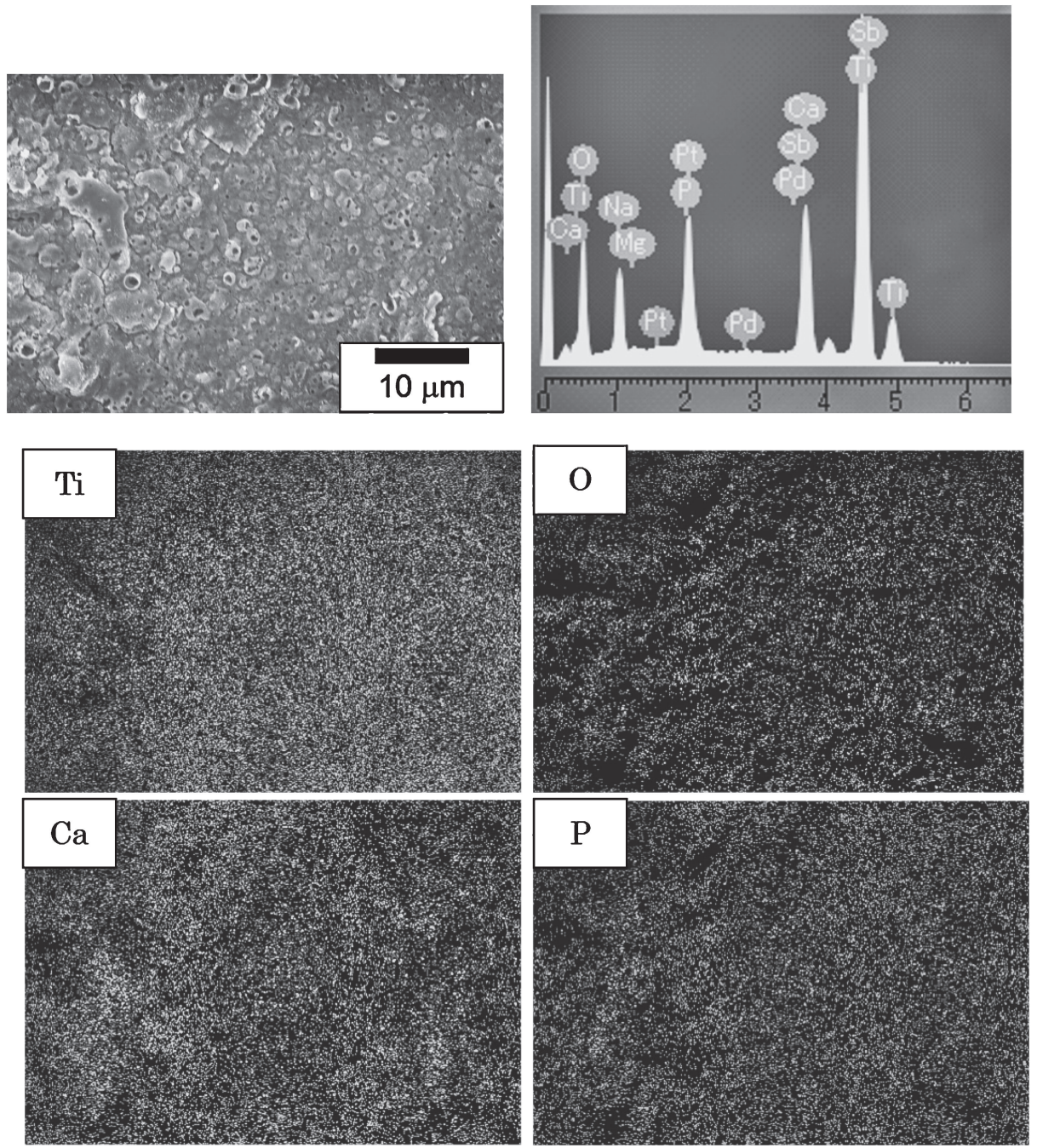

Fig. 9 EDX Spectra and 2D mapping of Ti, O, Ca and P for surface of HAp-AO-Ti anodized for 5 min. 

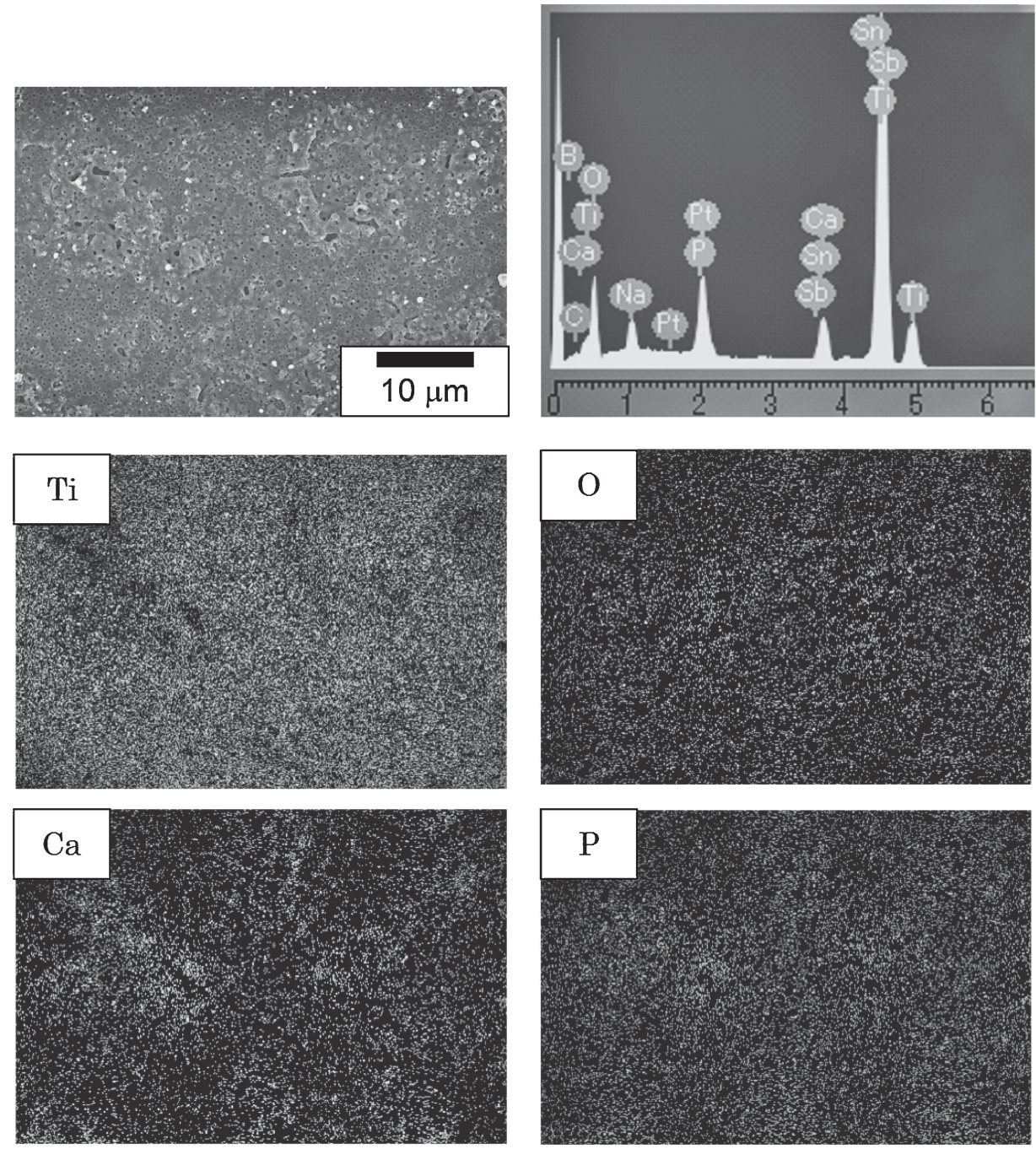

Fig. 10 EDX Spectra and 2D mapping of Ti, O, Ca and P for surface of HAp-Pulse-AO-Ti anodized at current density of $2 \mathrm{kA} / \mathrm{m}^{2}$ and frequency of $100 \mathrm{~Hz}$.

increasing current density and electrolysis time. Thus, increased biocompatibility is expected due to the uptake of HAp particles onto the film. Similarly, the EDX spectrum of the HAp-pulse-AO-Ti plate fabricated by pulse electrolysis shown in Fig. 10 reveals that $\mathrm{Ca}$ and $\mathrm{P}$ are present on the surface due to HAp fixation.

\subsection{XRD measurements}

Figure 11 shows XRD patterns of HAp-AO-Ti plates fabricated at various current densities and electrolysis times. Anatase $\mathrm{TiO}_{2}$ and rutile $\mathrm{TiO}_{2}$ were formed in almost equal amounts, which indicate that the heat generated by MAO with a direct current is insufficient to form highly crystalline rutile $\mathrm{TiO}_{2}$. However, some studies have indicated that anatase is preferable for artificial bone. ${ }^{20,21)}$ The XRD peaks for HAp particles reveal that HAp particles are incorporated in the oxide film with no loss of crystallinity. Interestingly, $\mathrm{CaTiO}_{3}$, which is known to play a key role in the induction of bone-like apatite through the formation of $\mathrm{Ti}-\mathrm{OH},{ }^{19,22,23)}$ was detected as clear peaks. $\mathrm{CaTiO}_{3}$ is considered to be produced by $\mathrm{Ca}^{2+}$ ions from HAp being incorporated in $\mathrm{Ti}$ substrates by the spark discharge energy.

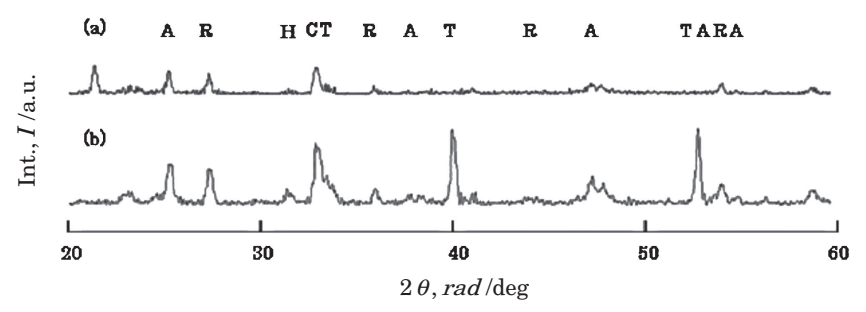

Fig. 11 XRD patterns of HAp-AO-Ti. Current density and anodic oxidation time (a) $2 \mathrm{kA} / \mathrm{m}^{2}, 90 \mathrm{~s}, \mathrm{HAp} 10 \mathrm{~g} / \mathrm{L}$ (b) $0.5 \mathrm{kA} / \mathrm{m}^{2}, 5 \mathrm{~min}$, HAp 10 g/L, A: Anatase, R: Rutile, T: Titanium, CT: Calcium titanate, H: Hydroxy apatate.

Figure 12 shows XRD patterns of a HAp-pulse-AO-Ti plate formed using a current density of $0 \pm 20 \mathrm{kA} / \mathrm{m}^{2}$ and a frequency of $100 \mathrm{~Hz}$. These XRD patterns contain anatase and rutile peaks, just as for the samples fabricated by direct current electrolysis. Although $\mathrm{CaTiO}_{3}$ was observed in the presence of HAp, just as for direct current electrolysis, the $\mathrm{CaTiO}_{3}$ peaks are considerably smaller, suggesting that many HAp particles are incorporated in the oxide layer. 


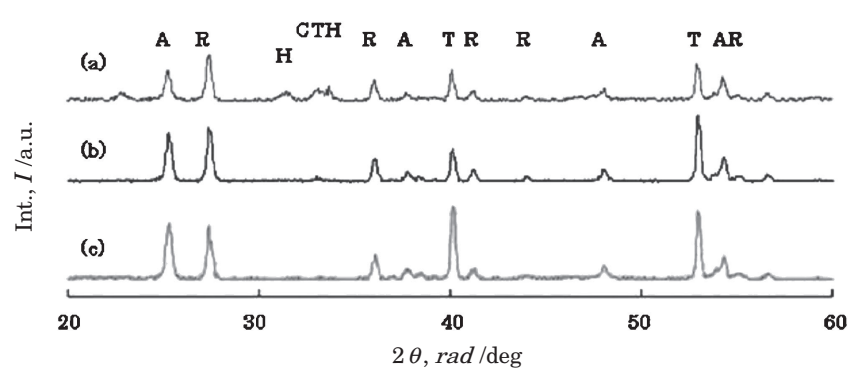

Fig. 12 XRD patterns of HAp-Pulse-AO-Ti. (a) HAp $10.0 \mathrm{~g} / \mathrm{L}$ (b) HAp $4.0 \mathrm{~g} / \mathrm{L}$ (c) HAp $2.0 \mathrm{~g} / \mathrm{L}$, A: Anatase, R: Rutile, T: Titanium, CT: Calcium titanate, H: Hydroxy apatate.

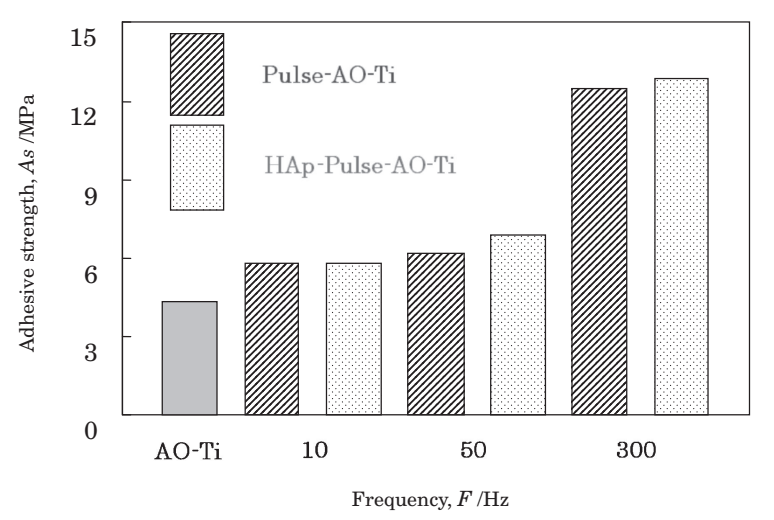

Fig. 14 Adhesive strength of AO-Ti, Pulse-AO-Ti and HAp-Pulse-AOTi plates.
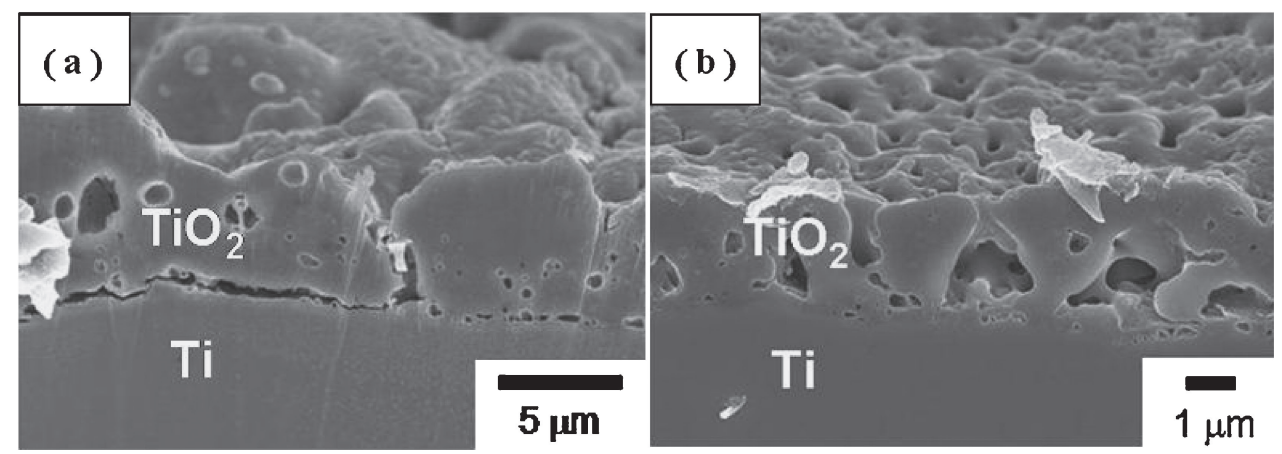

Fig. 13 Cross-section SEM micrograph of (a) AO-Ti and (b) Cross-section SEM micrograph of Pulse-AO-Ti.

\subsection{Cross-sectional SEM micrographs}

Figure 13(a) shows a cross-sectional SEM micrograph of an AO-Ti plate fabricated at a current density of $0.4 \mathrm{kA} / \mathrm{m}^{2}$ for $10 \mathrm{~min}$. It shows that the oxide layer is about $5 \mu \mathrm{m}$ thick and that many pores on the surface are interconnected and extend to the $\mathrm{Ti}$ substrate. Based on this, the pores are expected be useful for fabricating a scaffold suitable for forming new bone. On the other hand, a small gap was observed between the $\mathrm{TiO}_{2}$ layer and the Ti substrate. In direct current electrolysis, spark discharge is generated locally and moves continuously in a line as well as being generated in the gas near the anode. The heterogeneous movement of spark discharge and the gaseous emission may be responsible for the gap at the interface.

Figure 13(b) shows a cross-sectional SEM micrograph of the pulse-AO-Ti plate shown in Fig. 6(c). Unlike the AO-Ti plate, $\mathrm{TiO}_{2}$ was closely attached to the Ti substrate, with no gap at the interface. High temperatures are generated locally at places where spark discharge occurs. As mentioned above, spark discharge is generated locally along a line in direct current electrolysis. This may result in local heat generation, which may produce the gap due to the different thermal expansion coefficients of $\mathrm{TiO}_{2}$ and Ti. In contrast, smaller spark discharges are generated over the whole $\mathrm{Ti}$ plate in pulse electrolysis. This reduces the destruction of the $\mathrm{TiO}_{2}$ and $\mathrm{Ti}$ interface due to their different thermal expansion coefficients. In addition, many small interconnected pores with diameters of $0.2-1.0 \mu \mathrm{m}$ were observed in the $\mathrm{Ti}$ substrate.

\subsection{Adhesive strength}

Figure 14 shows the adhesive strength measurement results for $\mathrm{AO}-\mathrm{Ti}$, pulse-AO-Ti, and $\mathrm{HAp}-$ pulse-AO-Ti; AO-Ti was fabricated at $0.5 \mathrm{kA} / \mathrm{m}^{2}$ using pulse electrolysis with a current density of $2 \mathrm{kA} / \mathrm{m}^{2}$, a frequency of $10-100 \mathrm{~Hz}$, an electrolysis time of $20 \mathrm{~min}$, and $10 \mathrm{~g} / \mathrm{L} \mathrm{HAp}$. This figure shows that pulse-AO-Ti plate has a greater adhesive strength than the AO-Ti plate (5-6 MPa) and that the adhesive strength increases with increasing frequency. In addition, the HAp-pulse-AO-Ti plate has an almost identical adhesive strength as the pulse-AO-Ti plate, indicating that HAp has little effect on the adhesive strength. For the AO-Ti plate, the small gap between the $\mathrm{Ti}$ substrate and the $\mathrm{TiO}_{2}$ layer is considered to reduce the adhesive strength at the interface, as shown in Fig. 13(a). In contrast, the pulse-AO-Ti plate has no gap at the interface, as shown in Fig. 13(b). These observations can explain the higher adhesive strength of the pulse-AO-Ti plate than the AO-Ti plate. We confirmed that in the adhesive strength measurements for the HAp-AO-Ti and HAp-pulse-AO-Ti plates, the interface between the $\mathrm{TiO}_{2}$ layer/Ti substrate and between the $\mathrm{TiO}_{2}$ layer/adhesive detached, respectively.

\section{Conclusion}

The pulse-AO-Ti plate had a smoother and more uniform surface than the AO-Ti plate. Cross-sectional SEM micrographs revealed that while there are small gaps between $\mathrm{Ti}$ and $\mathrm{TiO}_{2}$ in $\mathrm{AO}-\mathrm{Ti}, \mathrm{TiO}_{2}$ adheres closely to $\mathrm{Ti}$ with no gap in 
the pulse-AO- $\mathrm{Ti}$ plate. In addition, the pulse- $\mathrm{AO}-\mathrm{Ti}$ plate had a significantly higher adhesive strength than the AO-Ti, which can be explained by it not having an interface gap. Thus, pulse electrolysis was demonstrated to be superior to direct current electrolysis for modifying surfaces of implant materials. In particular, HAp-pulse-AO-Ti plates with $\mathrm{CaTiO}_{3}$ and many interconnected pores in the surface film are promising for producing artificial bones.

\section{REFERENCES}

1) E. Conforto, B. O. Arronson, A. Salito, C. Crestou and D. Caillard: Mater. Sci. Eng. C 24 (2004) 611.

2) Y. G. Yang and J. L. Ong: J. Biomed. Mater. Res. 64 (2003) 509.

3) M. Metikos-Hukovic, E. Tkalcec, A. Kwokal and J. Piljac: Surf. Coat. Technol. 165 (2003) 40.

4) A. Citeau, J. Gucheux, C. Vinatier, P. Layrolle, T. P. Nguyen, P. Pilet and G. Daculsi: Biomaterials 26 (2005) 157.

5) G. Daculsi, N. Passuti, S. Mattin, C. Deudon, R. Z. Legeros and S. Raher: J. Biomed. Mater. Res. 24 (1990) 379.

6) K. de Groot, R. Geesink and C. P. Klein: J. Biomed. Mater. Res. 21 (1987) 1375.

7) A. Piattelli, A. Scarano, M. Piattelli and L. Calabrese: Biomaterials 10 (1996) 1015.

8) S. Yanaguchi, H. Takadama, T. Matsushita, T. Nakamura and T. Kokubo: J. Ceram. Soc. Japan 117 (2009) 1126.
9) H. Ishizawa and M. Ogino: J. Biomed. Mater. Res. 29 (1995) 65

10) L. H. Li, Y. M. Kong, H. W. Kim, H. E. Kim, S. J. Heo and J. Y. Koak: Biomaterials 25 (2004) 2867.

11) Y. T. Sul, C. B. Johansson, S. Petronis, A. Krozer, Y. Jeong, A. Wennerberg and T. Albrektsson: Biomaterials 23 (2002) 491.

12) Z. Zhongwei, X. Chen, A. Chen, G. Huo and H. Li: J. Mater. Sci. 44 (2009) 6310

13) F. Jin, P. K. Chu, K. Wang, J. Zhao, A. Huang and H. Tong: Mater. Sci. Eng. A 476 (2008) 78

14) M. Iwasaki, K. Kudo, K. Shimada, K. Matsuzaki and C. Hamanishi: Proc. 2008 MRS Fall Meeting Manuscript ID: 1132-Z08.R1.

15) J. Chen, Y. Shi, L. Wang, F. Yan and F. Zhang: Mater. Lett. 60 (2006) 2538.

16) E. Matykina, R. Arrabal, P. Skeidon and G. E. Thompsonm: Acta Biomater. 5 (2009) 1356.

17) J. Sun, Y. Han and X. Huang: Surf. Coat. Technol. 201 (2007) 5655.

18) Z. Zhao, X. X. Chen, A. Chen, M. Shen and S. Wen: J. Biomed. Mater. Res. 90A (2009) 438.

19) M. S. Kim, J. J. Ryu and Y. M. Sung: Electrochem. Commun. 9 (2007) 1886.

20) H. Maeda, T. Kasuga and M. Nogami: J. Euro. Ceram. Soc. 24 (2004) 2125.

21) M. Kawashita, X. Y. Cui, H. M. Kim, T. Kokubo and T. Nakamura: Key. Eng. Mater. (2004) 459.

22) W. H. Song, Y. K. Jun, Y. Han and S. H. Hong: Biomaterials 25 (2004) 3341.

23) T. J. Webster, C. Ergun, R. H. Doremus and W. A. Lanford: J. Biomed. Mater. Res. 67A (2003) 975. 